\title{
The Relationship Between Marketing Promotion of Historical Tourism and Tourist Motivation of Domestic Tourists: Case Study of KohYoh, Songkhla Province, Thailand
}

\author{
Weerawan Marangkun, Auntika Thipjumnong \\ Rajamangala University of Technology Srivijaya, Songkhla, Thailand
}

\begin{abstract}
Tourism is the significant hospitality industry of Thailand in terms of economic development and social development. According to the statistics, the number of tourists is increasing every year. In 2012, Thailand gained 5,515.94 million Baht from domestic tourists that increased 30.79\% from the previous year's income at the same period. This research is survey and cross-sectional study aimed to find the relationship between marketing promotion of historical tourism and tourist motivation of domestic tourists in KohYoh, Songkhla Province. The purpose of this study is to study the factors of marketing promotion affecting push and pull motivations of domestic tourists. The researcher applied structured questionnaire based on 5-level rating scale. The sample was selected by convenience sampling and calculated by Yamane’s (1967) Formula as 400 samples. The data collection consumed six months between July and December 2013. The data are analyzed by descriptive statistics, Pearson's Product Moment Coefficients and Multiple Regression to describe the relationship between marketing promotion of historical tourism and tourist motivation of domestic tourist. The result found that: (1) factors of marketing promotion affecting push motivation of domestic tourists at statistical significance of 0.01 are sales promotion $(t=13.534$, sig. $=0.000)$ and public relations $(t=3.426$, sig. $=0.001)$, which influenced the prediction power at $36.9 \%$ and std. error of the estimate $=0.559$; (2) factors of marketing promotion related to pull motivation of domestic tourists at statistical significance of 0.01 are public relations $(t=15.299$, sig. $=0.000$ ), promotion $(t=5.293$, sig. $=0.000)$, and advertising $(t=2.709$, sig. $=0.007)$, which influenced the prediction power at $45.8 \%$ and std. error of the estimate $=0.429$.
\end{abstract}

Keywords: marketing promotion, push motivation, pull motivation, domestic tourists

\section{Introduction}

Tourism is the significant hospitality industry of Thailand in terms of economic and social development. In 2012, the tourism generated 5,515.94 million Bath for Thailand. The National Statistic Office indicated that the number of tourists is increasing every year. In 2012, there are 1,492,589 tourists who traveled in Songkhla Province (1,119,724 domestic tourists and 372,865 foreign tourists) that calculated as 30.94\% increasing from 2011 (Department of Tourism, 2013). According to the survey of tourist behaviors in 2013, 22.5\% of domestic

Weerawan Marangkun, Assistant Professor, Marketing Department, Faculty of Business Administration, Rajamangala University of Technology Srivijaya. Email: wewiene1958@hotmail.com.

Auntika Thipjumnong, Assistant Professor, Marketing Department, Faculty of Business Administration, Rajamangala University of Technology Srivijaya. 
tourists and international tourists required traveling in Songkhla Province because of the interesting tourist destinations and the most popular activity is to visit the historical destination (Department of Tourism, 2014). The tourists preferred to impress with tourist destination and perceived the historical knowledge from local people based on awareness of cultural conservation. The local people would participate in tourism management and generated income to the local areas. The historical tourism included visiting historical parks, historic sites, and local architectures.

KohYoh is the island located in the lower of Songkhla Lake, Muang District, Songkhla Province far from Songkhla Town in southwest approximately 20 kilometers and 6 kilometers by boat. There are eight important historic sites in KohYoh: Kao Bo Temple, LaemPor Temple, KokPeaw Temple, Tai Yoh Temple, Kao Kuti Priest's Camp Site, Tai Kong Shrine and holy well (the well in front of the shrine), and Bo Lar (P. Marangkun, Chanintonsongkhla, \& W. Marangkun, 2012).

Thai public and private sectors promoted the historical tourism to motivate the tourists to visit Thailand by marketing promotion which included advertisement, public relations, sales promotion, and personal selling. Whereas, the result of survey represented that $42.7 \%$ or more of the domestic tourists perceived travel information from word of mouth, 15.6\% from television, and 3.1\% from Tourism Authority of Thailand (Tourism Statistic Record in the South of Thailand, National Statistical Office, 2011). Marangkun et al. (2012) found that it is difficult for KohYoh to generate marketing promotion because there are a lot of departments (both tourism departments and historical departments) which are concerned with the historical tourist destinations and due to lack of coordination among departments. Furthermore, some historic sites provided leaflets but lack interesting details or inspiring presentations that can motivate the tourists to visit and perceive the value of historical destinations. Kim, Chompton, and Botha (2000) explained the marketing communication and presented that the physical environment of historical tourism is a good opportunity to attract tourists to visit the destinations, whereas the failed marketing communication cannot inspire tourism activities.

Marketing promotion of historical tourism influenced the number of domestic tourists that is increasing presently. In addition, to establish and improve the environment of historical destinations and to understand the characteristics of domestic tourists and consumer behaviors is also very important. Pesonen, Komppula, Kronenberg, and Peters (2011) explained that consumer behaviors in tourism market depend on the understanding of push and pull motivations that could assist the marketer to improve and apply the customer decision-making process and predict consumer behaviors in the future. According to Correia, Kozak, and Ferradeira (2013), push and pull motivations are related to customer satisfaction and tourist behaviors and they are the main factors influencing decision-making when the tourists considered the tourist destination.

Therefore, to understand marketing promotion of historical tourism that influences domestic tourists' motivation who travel in KohYoh could establish the process, measure, and provide the appropriate hospitality with domestic tourists. The purpose of this study is to study the factors of marketing promotion affecting push and pull motivations of domestic tourists. The researcher studied the relationship between independent variable as marketing promotion (advertising, public relation, sales promotion, and personal selling) and push and pull travel motivation of domestic tourists. Then, measurements for push and pull motivations are developed from the existing literature. 


\section{Literature Review}

\section{Travel Motivations in Historical Tourism}

The tourist motivation studies are the gathering of ideas and approaches constituting what Cohen (1974) referred as a "fuzzy set" of definitions and descriptions. Motivation is commonly seen as the driving force behind all actions. Motivation is a dynamic process of internal psychological factors encompassing the needs, wants, and goals of an individual (Jennifer \& Baum, 2007). It has been used to refer to internal factors that direct and integrate a person's behavior for potential satisfaction.

Motive for tourism is consequently defined as "the set of needs which predispose a person to participate in a touristic activity”. Motivation occurs when an individual wants to satisfy a need (Mehmetoglu \& Normann, 2013). Maslow's (1970) hierarchical theory of motivation was one of the most applied in the tourism literature. The theory was modeled as a pyramid whose base consists of the physiological needs, followed by higher levels of psychological needs and the need for self-actualization. Numerous tourism scholars have attempted to modify the model empirically, with the notable success by Dann (1981), who proposed a tourism motivation model that mirrors the model of Maslow, but free of prepotency assumption. A review of the previous literatures on tourist motivation indicates that the analysis of motivations is based on the significance of tourist motivation because when the host impressed the tourists, it could encourage local economics and advocate the local historical tourist destination. Jittangwatana (2005) described historical tourism as that the tourists have motivation to visit museum or archaeological site that used to be prosperous in the past. The tourists may visit the monument, temple, place of worship, and the palaces including sound and light show that represent the famous and significant event in history.

Narayan, Rajendran, and Sai (2008) explained the indicators of the historical tourist destination quality that influenced tourist motivation which included the tourists' perception of the relaxation atmosphere, the beauty of tourist destinations, and the aptness of tourist destinations and these experiences are determined as core-tourism experience. The study of Proyrungroj (2015) found that both domestic tourists and international tourists have the same tourist motivation as seeking for the new experiences, preferring for self-development, and requiring participating in interesting activity. The different tourist motivations between domestic tourists and international tourists are: require the inner happiness, prefer to help other people, need to learn in depth Thai culture, seek for new friends, and seek for a chance to travel to Thailand. Charitngam, Lertputtaruk, and Deebhijarn (2010) explained that the effective public relation of tourist destination could enhance the tourist motivation. The tourist motivation of historical tourism affected tourist behaviors and convey to decision-making to select tourist destination. Therefore, the tourism organization should respond to the tourist needs. According to the study of Panyachit and Wanitchanon (2015), historical tourists have several similarities: they are most often motivated by opportunities to learn and explore historical or different cultures, participate in outdoor activities, and search for peace and solitude. But differences can also be found, especially in relation to expectations towards learning activities, heritage or other destination attributes.

\section{Push and Pull Motivations in Historical Tourism}

Several historical tourism segmentation studies have studied the motivations of the travelers who visit KohYoh. Especially in benefit segmentation, the studies of push and pull motivations are often incorporated into same factor analysis which, according to Snepenger, King, Marshall, and Uysal (2006), is not recommended. Instead, they suggested that researchers who are interested in the link between push and pull 
motivations should develop motivational structures and benefit structures independently in separate factor analyses (Snepenger et al., 2006).

Push and pull motivations were also analyzed in several studies referring to customer value construct in tourism; for example, Kim, Noh, and Jogaratnam (2007); Mohammad and Som (2010); Pesonen et al. (2011); Li and Bray (2007); Taylor and Shanka (2008). These researchers studied perceived visitor value in a context of heritage tourism site development. Li and Bray (2007) studied in the case of cross-border flows of students for higher education: push-pull factors and motivations of mainland Chinese students in Hong Kong and Macau. They found that the paper begins by noting the literature on the ways that push and pull factors influence student mobility, and then turns to motivations in pursuit of academic and professional growth, economic benefit, individual internationalization, and enhanced social status. However, motivation is conceptually described as "a state of need, a condition that serves as a driving force to display different kinds of behavior toward certain types of activities, developing preferences, arriving at some expected satisfactory outcome” (K. F. Backman, S. J. Backman, Uysal, \& Sunshine, 1995). Dawson and Henley (2012) argued that the concept of product bundles is used to refer to the perceived importance of the interaction between push and pull items of motivations. Klenosky (2002) viewed push factors as being associated with "whether to go", while pull factors are related to "where to go" decided at two separate points in time. It is important, however, to note that the two sets of factors or forces are not independent even if they seem to be conceptually distinguished from each other.

Bansal and Eiselt (2004) studied the relationship between tourism motivations and planning in Canada. They used a survey that allowed space for qualitative answers and comments and found five tourist motives: climate, relaxation, adventure, personal, and educational. The results of their study showed that tourist motivations affect the choice of region together with the image of all regions and travel companions (Kanagaraj \& Bindu, 2013). After the region is chosen, tourists make detailed plans about their vacation and then decide the destination based on what the destination has to offer, i.e., pull motivations. Tsaur, Saenchan, and Weerapaiboon (2014) made an analysis of push and pull travel motivational youth traveler: A case study of Thailand and Taiwan. They used questionnaire to measure travel motivations (push and pull motivations) of people traveling to different countries. The results showed that the most important travel push motive factors of international youth travelers were knowledge, adventure, and relaxation. They decided to travel to Thailand and Taiwan due to different push motivations of knowledge, sport, adventure, and relaxation. On the other hand, pull motivation factors were scenery, cuisine, local custom and culture, price of goods, safe social environment, and historic relics. According to Baloglu and Uysal (1996), it is necessary to understand both push and pull motivations and the relationship between them to market a particular destination effectively.

The previous literature reviews represented that the analysis of tourism motivation would be based on push and pull factors. This study explained the concept of push and pull dimension as the tourists decide to travel when they are pushed by their internal motive and pulled by the external forces such as destination attributes. Most of the push factors which are origin-related are intangible or intrinsic desires of the individual travelers including gaining knowledge, seeking relaxation, enhancing relation, and fulfilling spiritual needs. Pull factors, on the contrary, are those that emerge as a result of the attractiveness of a destination as it is perceived by the travelers. They include tangible resources and travelers' perception and expectation such as novelty, benefit expectation and marketed image of the destination, including architecture, historical and cultural events and activities, variety seeking, and heritage sites. 


\section{Marketing Promotion in Historical Tourism}

The travel decision-making of individuals is an important theme in travel and tourism research. In particular, travel marketers and researchers have sought to understand how and why consumers make either domestic or international travel decisions in terms of push and pull motives (e.g., Kim \& Lee, 2002; Sirakaya, Uysal, \& Yoshioka, 2003; Prasopphan \& Sutamuang, 2014). Klenosky (2002) found that travel motivation as a basis for predicting why individuals travel is recognized as playing a crucial role in segmenting the travel market and developing travel products. An important element of this research involves identifying and describing target markets in sufficient detail to suggest product development and marketing communications strategies. Market segments are an essential means of identifying groups of consumers who have similar attitudes and perspectives toward particular stimuli (e.g., product attributes, advertising messages, pricing). To effectively develop travel products, travel marketers need to understand the distinctive and unique characteristics of travelers. For instance, Prasopphan and Sutamuang (2014) studied in the case motivation factors for choosing overseas travel service. The result of hypothesis testing is of statistical significance and found that provider factors; brand image, brand loyalty and trust had an effect on traveler's motivation for choosing overseas travel service. K. Poulis and E. Poulis (2011) in their study, Promotional Channels of FMCG Firms and Tourism: A Standardization/Adaptation Perspective, aimed to clarify the influence of a tourism-oriented environment on the promotional channel strategies of fast-moving consumer goods (FMCG) firms. Findings show that most firms utilize adapted promotional channels due to the influence of structural characteristics of the tourism industry and tourists' modes of behavior. These researches are related to Suwanthamma's (2009) study Advertising and Public Relation Factors Affecting Audiences Viewing Behavior on International Film in Bangkok Area. The result found that factors motivating the audiences to view the international film are: for relaxation, they perceived the worth, and for entertainment respectively. On the other hand, the study of Hadija, Barnes, and Hair (2012) found that the users of online social networks do not dislike advertisements, but just simply do not notice them. Other content found in online social networks mitigates the attractiveness of the advertisements. Hence, the respondents reported that the brand recognition in online social networks was found to be much lower than the one created through other media channels.

Lubik, Lim, Platts, and Minshall (2012) studied market-pull and technology-push in manufacturing start-ups in emerging industries. Their result found that marketing opportunity consisted from the public relation is pull motivation for the producers to participate in the industry whilst push motivation drives the operation. Guan, Luo, and Tang (2015) described push and pull motivations to be the reason for making decisions of the consumer. Wang (2004) studied push and pull factors in mountain resorts and found that push and pull motivations are different but both of them are important factors for market expansion in the future. Push and pull motivations help the marketers to understand tourist behavior and predict appropriate marketing plans to respond to tourist needs.

A diagram of the model proposed in this study is shown in Figure 1. Based on push and pull motive literature, marketing promotion variables included advertising, public relation, sales promotion, and personal selling. The variables are integrated and viewed as potentially significant factors influencing push and pull motivations. These explanations justify the following hypothesis:

H1: Marketing promotion factor is positively related with push motivation of domestic tourists.

H1a: Advertising is positively related to push motivation.

H1b: Public relation is positively related to push motivation. 
H1c: Sales promotion is positively related to push motivation.

H1d: Personal selling is positively related to push motivation.

H2: Marketing promotion factor is positively related with push motivation of domestic tourists.

H2a: Advertising is positively related to pull motivation.

H2b: Public relation is positively related to pull motivation.

H2c: Sales promotion is positively related to pull motivation.

H2d: Personal selling is positively related to pull motivation.

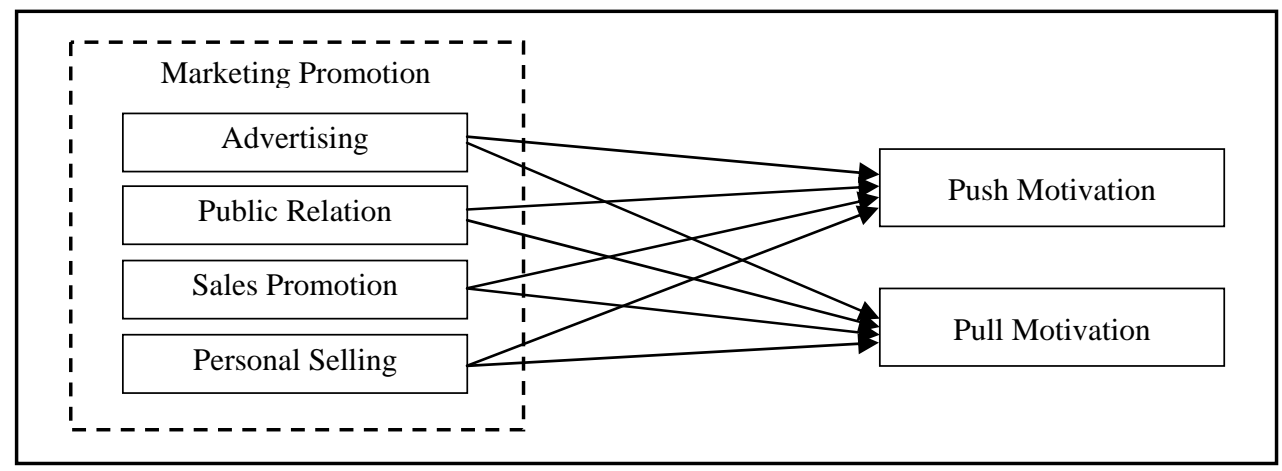

Figure 1. Proposed model of push and pull motivation.

\section{Research Methodology}

This research is survey and cross-sectional study aimed to find the relationship between marketing promotion of historical tourism and tourist motivation (push and pull motivations) of domestic tourists in KohYoh, Songkhla province. The framework of this model is to study the factors of marketing promotion affecting push and pull motivations of domestic tourists.

\section{Data Collection}

The data are collected by structural questionnaire to identify marketing promotion (advertising, public relation, sales promotion, and personal selling) affecting domestic tourists who prefer the historical tourism. The questionnaire is responded by domestic tourists after the pre-test with 30 domestic tourists who travel in historical attractions in KohYoh, Songkhla province. The confidence of the whole questionnaire is obtained by Alpha coefficient which is found to be 0.84 .

The sample consists of domestic tourists who travel to historic sites in KohYoh, Songkhla province including Kao Bo Temple, LaemPor Temple, KokPeaw Temple, Tai Yoh Temple, Kao Kuti Priest’s Camp Site, Tai Kong Shrine and holy well (the well in front of the shrine), and Bo Lar. The samples were selected by convenience sampling and calculated by Yamane's (1967) Formula as 400 samples. The data collection consumed six months between July and December 2013.

The dataset for push and pull motivation study collected by questionnaire was divided into seven thematic parts (description of domestic tourists, push and pull motivations, advertising, public relation, sales promotion, and personal selling) which gave indications about the marketing promotion and competencies and even some details about external determinants through multiple choice items, Likert scales by Rensis A. Likert and dummy variables with the scores ranging from 1 to 5 ( 1 = "Not important at all", 2 = "Not very important", $3=$ "Important”, 4 = "Very important”, and 5 = "Essential”). 


\section{Measures}

Dependent variable: push and pull measures. When analyzing papers about push and pull motivation measures, there are four sections of push motivation including domestic tourists require knowledge, seeking relaxation, enhancing relation and fulfilling spiritual needs and five sections of pull motivation including interesting architecture, historical and cultural events and activities, variety seeking and heritage sites.

Independent variables: marketing promotion determinants of push-pull motivation. These include advertising, public relation, sales promotion, and personal selling.

Advertising. To measure the advertising affecting push and pull motivations in this study, there are six media selected including television/radio, magazine/journal, document/letter, internet, signboard, and newspaper. The study described the influence media to motivate the tourists to travel in historical sites.

Public relation. There are five items to measure public relation of historical tourism in KohYoh, Songkhla province including operating parade in important festival, providing fieldtrip for tourists/mass media, inviting the expert to narrate local history in historic sites, contacting the travel agency, and operating activities in special occasions. These activities could help the tourists to make a decision when they selected the destinations.

Sales promotion. There are four items of sales promotion affecting tourists' behaviors including offering prize, providing tourist program in special price, exhibiting tourism booth/tourist activities, and arranging the contest or competition, e.g., photo contest.

Personal selling. There are three items of personal selling of historic tourist destination in KohYoh, Songkhla province affecting tourist behaviors, including using salesperson to promote tourism program, selling tourism program in exhibition, and using salesperson to present tourism program to local tourism entrepreneurs and travel agencies.

\section{Analysis}

Data analysis was carried out using SPSS 17.0 statistical software to analyze the percentage, mean, standard deviation, Pearson correlation coefficient, and stepwise regression analysis respectively.

\section{Results}

\section{Responses}

According to data collection, there are 400 domestic tourists who travel to historic sites in KohYoh, Songkhla province as shown in Table 1.

As shown in Table 1, most of the respondents are female (56.0\%), while male respondents are $44.0 \%$. Considering age, most of the respondents aged between 21-30 years (37.75\%), followed by 41-50 years (22.75\%), and 31-40 years (22.50\%) respectively. The education levels of most domestic tourists are some college (42.25\%), high school (28.25\%), and college graduate $(24.00 \%)$. Most of the domestic tourists are residents of Songkhla province (56.25\%) and residents of the south of Thailand (28.50\%). The result found that most of the domestic tourists prefer to seek information about historical sites in KohYoh by using word of mouth (50.30\%), internet (42.50\%), and television/radio (35.50\%) respectively.

\section{Analysis of Push and Pull Motivations}

According to the study, the result found that push motivation is a significant internal force to motivate the tourists to travel to historical sites in KohYoh is important level (Mean = 3.95) based on Best (1981) as shown in Table 2. 
Table 1

Profile of Domestic Tourists

\begin{tabular}{|c|c|c|c|}
\hline Variable & & $N$ & Percent (\%) \\
\hline \multirow{2}{*}{ Gender } & Male & 176 & 44.00 \\
\hline & Female & 224 & 56.00 \\
\hline \multirow{6}{*}{ Age } & Less than 20 years old & 29 & 7.25 \\
\hline & $21-30$ years old & 151 & 37.75 \\
\hline & $31-40$ years old & 90 & 22.50 \\
\hline & $41-50$ years old & 91 & 22.75 \\
\hline & 51-60 years old & 26 & 6.50 \\
\hline & More than 60 years old & 13 & 3.25 \\
\hline \multirow{5}{*}{ Level of education } & Some high school & 10 & 2.50 \\
\hline & High school & 113 & 28.25 \\
\hline & Some college & 169 & 42.25 \\
\hline & College graduate & 96 & 24.00 \\
\hline & Postgraduate & 12 & 3.00 \\
\hline \multirow{5}{*}{$\begin{array}{l}\text { Domestic tourist's place of } \\
\text { origin }\end{array}$} & Songkhla province & 225 & 56.25 \\
\hline & Southern region & 114 & 28.50 \\
\hline & Central region & 31 & 7.75 \\
\hline & Eastern region & 21 & 5.25 \\
\hline & Northern region & 9 & 2.25 \\
\hline \multirow{7}{*}{ Type of data sources } & Word of mouth & 201 & 50.30 \\
\hline & Tourism Authority of Thailand & 69 & 17.30 \\
\hline & Tour agencies & 31 & 7.80 \\
\hline & Television/radio & 142 & 35.50 \\
\hline & Magazine/journal & 109 & 27.30 \\
\hline & Tourism exhibition & 21 & 5.30 \\
\hline & Internet & 170 & 42.50 \\
\hline
\end{tabular}

Table 2

Mean and SD Values of Push Motivation Items

\begin{tabular}{llll}
\hline Reasons for visiting KohYoh & Mean & SD & Level \\
\hline To experience new and different lifestyles or traditions & 3.94 & 0.732 & Important \\
To relax spiritually & 3.94 & 0.789 & Important \\
To exchange custom and traditions & 4.02 & 0.858 & Important \\
To reconnect spiritual roots & 3.91 & 0.793 & Important \\
Total & 3.95 & 0.793 & Important \\
Cronbach's alpha $=0.796$ & & & \\
\hline
\end{tabular}

Table 3

Mean and SD Values of Pull Motivation Items

\begin{tabular}{llll}
\hline Reasons for visiting KohYoh & Mean & SD & Level \\
\hline Vernacular architecture & 4.18 & 0.734 & Important \\
Historical sites & 4.14 & 0.769 & Important \\
Culture, arts, and traditions & 4.27 & 0.731 & Very important \\
Exotic atmosphere & 4.29 & 0.742 & Very important \\
Temple, Buddha statue and Pagoda & 4.23 & 0.752 & Very important \\
Total & 4.22 & 0.746 & Very important \\
Cronbach's alpha $=0.839$ & & & \\
\hline
\end{tabular}


According to the result, pull motivation is very important (Mean $=4.22$ ) for the tourists to determine the destination. Nevertheless, the tourists would select the destinations by the entity of each destination as shown in Table 3.

The analysis of correlation between the advertising, public relation, sales promotion, and personal selling with push motivation by Pearson correlation coefficients is shown in Table 4.

Several Pearson correlations for the independent, dependent, and control variables have been computed. Table 4 shows that the strongest correlations with the dependent variable (push motivation) have been found with regard to sales promotion of historical tourism (H1c, $r=0.592, p<0.001$ ). The same is applied to the public relation (H1b, $r=0.280, p<0.001$ ) devoted to push motivation for the two samples. Most of the correlation coefficients have the expected sign with two independent variables evidencing a positive correlation with the dependent variable.

Table 4

Bivariate Analysis with Push Motivation: Pearson Correlation

\begin{tabular}{lcccc}
\hline & Advertising & Public relation & Sales promotion & Personal selling \\
\hline Advertising & - & & & \\
Public relation & 0.039 & - & & \\
Sales promotion & 0.009 & $0.250^{* *}$ & - & - \\
Personal selling & -0.003 & $-0.158^{* *}$ & -0.031 & 0.033 \\
Push motivation & 0.007 & $0.280^{* *}$ & $0.592^{* *}$ & \\
\hline
\end{tabular}

Note. ${ }^{* *}$ Correlation is significant at the 0.01 level (2-tailed). ${ }^{*}$ Correlation is significant at the 0.05 level (2-tailed).

Table 5

Bivariate Analysis with Pull Motivation: Pearson Correlation

\begin{tabular}{lcccl}
\hline & Advertising & Public relation & Sales promotion & Personal selling \\
\hline Advertising & - & & & \\
Public relation & 0.039 & - & & \\
Sales promotion & 0.009 & $0.250^{* *}$ & - & - \\
Personal selling & -0.003 & $-0.158^{* *}$ & -0.031 & $-0.115^{*}$ \\
Pull motivation & $0.125^{*}$ & $0.640^{* *}$ & $0.350^{* *}$ & \\
\hline
\end{tabular}

Note. $^{* *}$ Correlation is significant at the 0.01 level (2-tailed). ${ }^{*}$ Correlation is significant at the 0.05 level (2-tailed).

Considering the specific marketing promotion of historical tourism, several Pearson correlations for the independent, dependent, and control variables have been computed. Table 5 shows that the strongest correlations with the dependent variable (pull motivation) have been found with regard to public relation (H2b, $r=0.640, p<0.001$ ). The same is applied to the sales promotion (H2c, $r=0.350, p<0.001$ ) and advertising (H2a, $r=0.125, p<0.005$ ) devoted to marketing promotion for four samples. Most of the correlation coefficients have the expected sign with three independent variables evidencing a positive correlation with the dependent variable. Only independent variable, personal selling (H2d, $r=-0.115, p<0.005$ ) has a negative relation with the dependent variable (pull motivation).

Stepwise multiple regression analysis of advertising, public relation, sales promotion, and personal selling which affected push motivation is shown in Table 6. 
Table 6

Results of Stepwise Regression Analysis

\begin{tabular}{|c|c|c|c|c|c|}
\hline Variable & $b$ & $\beta$ & $S E_{b}$ & $t$ & Sig. \\
\hline \multicolumn{6}{|c|}{ Independent variables } \\
\hline Sales promotion & 0.546 & 0.546 & 0.040 & 13.534 & 0.000 \\
\hline Public relation & 0.166 & 0.166 & 0.048 & 3.426 & 0.001 \\
\hline \multicolumn{6}{|c|}{ Dependent variable } \\
\hline Push motivation & & & & & \\
\hline
\end{tabular}

The stepwise multiple regression analysis explained an obvious understanding of the determinants that significantly contribute to each push measure within a historical tourism context. Preliminary statistical testing ensured compliance with regression assumptions. A discussion of each stepwise regression equation provides insight into the key determinants of each motivation measure within a historical tourism context. The theoretical push motivation was specified as a linear equation and estimated in three steps, using an ordinary least squares regression procedure. Initially, we included all independent variables, namely, advertising, public relation, sales promotion, and personal selling. Of the two variables, the marketing promotion measure of domestic tourists was best explained by sales promotion and public relation. As indicated in Table 6, these variables explain $36.60 \%\left(R^{2}=0.366\right)$ of the variance in the push motivation of domestic tourists. Analysis of the regression coefficients indicates that while sales promotion $(\beta=0.546, p<0.000)$ and public relation ( $\beta=0.166, p<0.001$ ) relate to the push motivational measure. And std. error of the estimate is 0.559 . The result represents that there are other factors (calculated as 63.40\%), except sales promotion and public relation, which affected push motivation of domestic tourists.

Stepwise multiple regression analysis of advertising, public relation, and sales promotion which affected pull motivation is shown in Table 7.

Table 7

Results of Stepwise Regression Analysis

\begin{tabular}{|c|c|c|c|c|c|}
\hline Variable & $b$ & $\beta$ & $S E_{b}$ & $t$ & Sig. \\
\hline \multicolumn{6}{|c|}{ Independent variables } \\
\hline Public relation & 0.569 & 0.585 & 0.037 & 15.299 & 0.000 \\
\hline Sales promotion & 0.164 & 0.202 & 0.031 & 5.293 & 0.000 \\
\hline Advertising & 0.093 & 0.100 & 0.034 & 2.709 & 0.007 \\
\hline \multicolumn{6}{|c|}{ Dependent variable } \\
\hline Pull motivation & & & & & \\
\hline
\end{tabular}

According to stepwise multiple regression analysis, the result found three predictive variables: public relation, sales promotion, and advertising separated from four variables of historical tourism promotion. All of the three variables have joint predictive power that could predict pull motivation of domestic tourists as indicated in Table 7 . The variables explained $45.30 \%$ of the variance in the pull motivational measure of domestic tourists. Analysis of the regression coefficients indicates that while public relation $(\beta=0.585$, $p<0.000)$, sales promotion $(\beta=0.202, p<0.000)$, and advertising $(\beta=0.100, p<0.007)$ positively relate to the pull motivational measure. The result represented that except sales promotion and public relation, there are other factors calculated in $54.70 \%$ could affect the pull motivation of domestic tourists. 


\section{Discussion}

This study described the relationship between marketing promotion including advertising, public relation, sales promotion, and personal selling of historical tourism in KohYoh and push and pull motivations of domestic tourists based on two hypotheses:

The stepwise multiple regression analysis of push motivation found that advertising and public relation have a positive relationship with push motivation of domestic tourist's decision-making to select historic sites at statistical significance of 0.000 and 0.001 (H1a and H1b) respectively. Manin and Waiwassana (2015) in their study, Thai, European and Scandinavian Tourists' Perceptions Motivation and Desire to Travel in Ranong Province, found that domestic tourists perceived tourism information from the advertising, e.g., book/magazine, search engine, website, and Facebook. To generate appropriate tourism promotion plan, the concerned organizations should provide credible advertising and public relation because effective marketing promotion could distinctly reach the target market. Domestic tourists perceived marketing promotion of historical tourism by advertising and public relation of location, information, and environment of tourist destination by various media and these activities are psychological factors that motivate the tourists to travel.

The stepwise multiple regression analysis pull motivation found that advertising and public relation have a positive relationship with pull motivation to select historic site at statistical significance of 0.000 and 0.007 (H1a and H1b) respectively. Prasopphan and Sutamuang (2014) in their study, Motive Factors for Choosing Overseas Travel Service, found the positive relationship between integrated marketing communication and tourist motivation for choosing service, especially tourist attractions that provided the staffs to suggest the information. Therefore, to encourage tourism promotion, the provider should emphasize the pull motivation, focusing not only on promoting the tourist destination image. Furthermore, the provider should promote historical tourism in variety sides, e.g., accommodations, religious tourism, historic site, and outstanding local culture, according to Yingyoun and Lertputtharak (2014). Therefore, the effective advertising and image of tourist destination are the significant pull motivations whilst public relation by the official about the quality of hospitality, fair price, affordable price, food, and safety is pull motivation that emphasizes the decision-making to select accommodation, public transportation, public health and hygiene, and other sides of tourist destination.

\section{Conclusion}

The empirical results of this study provide tenable evidence that tourist motivation is closely associated with destination's marketing promotion and image of historic sites. As tourism is increasingly becoming an important sector in Songkhla province's economy, it can be clear that major findings of this study have significant policy and managerial implications for historical site's core attractions and support services in tourism. These are fundamental in extending length of stay, increasing satisfaction, and enhancing destination loyalty of domestic tourists.

Nevertheless, marketing promotion is not only the factor that affects tourists' motivation and motivation is one of the various variables that determines tourist destination.

Therefore, Thai public and private sectors concerned with tourism industry should promote KohYoh as a historical site by presenting the good image and indicating the entity culture via the magazine, local media, internet, exhibition, and road show since these media could directly reach the domestic tourists. 


\section{References}

Backman, K. F., Backman, S. J., Uysal, M., \& Sunshine, K. M. (1995). Event tourism: An examination of motivations and activities. Festival Management and Event Tourism, 3(1), 15-24.

Baloglu, S., \& Uysal, M. (1996). Market segments of push and pull motivations: A canonical correlation approach. International Journal of Contemporary Hospitality Management, 8(3), 32-38.

Bansal, H., \& Eiselt, H. A. (2004). Exploratory research of tourist motivations and planning. Tourism Management, 25(3), 387-396.

Best, J. W. (1981). Research in education. New Jersey, NJ: Prentice-Hall.

Charitngam, P., Lertputtaruk, S., \& Deebhijarn, S. (2010). The study of potential tourism development community new home market. Chachoengsao, Thailand. Journal of Commerce Boorapa Review, 4(2), 59-73.

Cohen, E. (1974). Who is a tourist? A conceptual clarification. Sociological Review, 22(4), 527-555.

Correia, A., Kozak, M., \& Ferradeira, J. (2013). From tourist motivations to tourist satisfaction. International Journal of Culture, Tourism and Hospitality Research, 7(4), 411-424.

Dann, G. M. (1981). Tourist motivation an appraisal. Annals of Tourism Research, 8(2), 187-219.

Dawson, C., \& Henley, A. (2012). "Push” versus “pull” entrepreneurship: An ambiguous distinction? International Journal of Entrepreneurial Behavior \& Research, 18(6), 697-719.

Department of Tourism Ministry of Tourism and Sports. (2014). The survey of travel behaviors proportion of domestic tourism in 2014.

Department of Tourism. (2013). Internal tourism in Songkhla. Retrieved from http://tourism2.tourism.go.th/home/details/11/221/24340

Guan, L., Luo, Y., \& Tang, L. R. (2015). An exploratory study of decision makers for choosing wedding banquet venues: Push and pull motivations. International Journal of Tourism Cities, 1(2), 162-174.

Hadija, Z., Barnes, S. B., \& Hair, N. (2012). Why we ignore social networking advertising. Qualitative Market Research: An International Journal, 15(1), 19-32.

Jennifer, K. L. C., \& Baum, T. (2007). Motivation factors of ecotourists in ecolodge accommodation: The push and pull factors. Asia Pacific Journal of Tourism Research, 12(4), 349-364.

Jittangwatana, B. (2005). Industrial tourism business day of the dead. Bangkok: C.P. Book Standard.

Kanagaraj, C., \& Bindu, T. (2013). An analysis of push and pull travel motivations of domestic tourists to Kerala. International Journal of Management \& Business Studies, 3(2), 112-118.

Kim, S., Chompton, J. L., \& Botha, C. (2000). Responding to competition: A strategy for Sun/Lost City, South Africa. Tourism Management, 21(1), 33-41.

Kim, K., Noh, J., \& Jogaratnam, G. (2007). Multi-destination segmentation based on push and pull motives: Pleasure trips of students at a US university. Journal of Travel \& Tourism Marketing, 21(2/3), 19-32.

Kim, S. S., \& Lee, C. K. (2002). Push and pull relationships. Annals of Tourism Research, 29(1), 257-260.

Klenosky, D. B. (2002). The "pull” of tourism destinations: A means-end investigation. Journal of Travel Research, 40(4), 385-395.

Li, M., \& Bray, M. (2007). Cross-border flows of students for higher education: Push-pull factors and motivations of mainland Chinese students in Hong Kong and Macau. Higher Education, 53(6), 791-818.

Lubik, S., Lim, S., Platts, K., \& Minshall, T. (2012). Market-pull and technology-push in manufacturing start-ups in emerging industries. Journal of Manufacturing Technology Management, 24(1), 10-27.

Manin, W., \& Waiwassana, R. (2015). Thai, European and Scandinavian tourists' perceptions motivation and desire to travel in Ranong Province. The National Conference of Suan Sunandha Rajabhat University, pp. 203-212.

Marangkun, P., Chanintonsongkhla, M., \& Marangkun, W. (2012). The identity management landscape of KohYoh.

Maslow, A. H. (1970). Motivation and personality (2nd ed.). New York, NY: Harper and Row.

Mehmetoglu, M., \& Normann, Ø. (2013). The link between travel motives and activities in nature-based tourism. Tourism Review, 68(2), 3-13.

Mohammad, B. A. A. H., \& Som, A. P. M. (2010). An analysis of push and pull travel motivations of foreign tourists to Jordan. International Journal of Business and Management, 5(12), 41-50.

Narayan, B., Rajendran, C., \& Sai, L. P. (2008). Scales to measure and benchmark service quality in tourism industry: A second-order factor approach. Benchmarking: An International Journal, 15(4), 469-493. 
National Statistical Office. (2012). Tourism statistic record in the South of Thailand, 2011.

Panyachit, S., \& Wanitchanon, P. (2015). Buddhist and culture tourism of Southern Region in Thailand: Development routes and impact. Journal of Social Science Srinakharinwirot University, 18(10). 247-262.

Pesonen, J., Komppula, R., Kronenberg, C., \& Peters, M. (2011). Understanding the relationship between push and pull motivations in rural tourism. Tourism Review, 66(3), 32-49.

Poulis, K., \& Poulis, E. (2011). Promotional channels of FMCG firms and tourism: A standardisation/adaptation perspective. EuroMed Journal of Business, 6(1), 5-23.

Prasopphan, H., \& Sutamuang, K. (2014). Motivation factors for choosing overseas travel service. Business Review, 8(1), 37-50.

Proyrungroj, R. (2015). The motivations of Thai and Western tourists in participating in volunteer tourism vacation in Bangkok. Journal of Research for Sustainable Development, 323-331.

Sirakaya, E., Uysal, M., \& Yoshioka, C. F. (2003). Segmenting the Japanese tour market to Turkey. Journal of Travel Research, 41(3), 293-304.

Snepenger, D., King, J., Marshall, E., \& Uysal, M. (2006). Modeling Iso-Ahola’s motivation theory in the tourism context. Journal of Travel Research, 45(2), 140-149.

Suwanthamma, N. (2009). Advertising and public relation factors affecting audiences viewing behavior on international film in Bangkok area. Journal of Education, 10(1).

Taylor, R., \& Shanka, T. (2008). Visitor value perception of a heritage tourism site development: A case study. Tourism Analysis, 13(2), 131-142.

Tsaur, S. H., Saenchan, K., \& Weerapaiboon, W. (2014). An analysis push and pull travel motivational youth traveler: A case study of Thailand and Taiwan. Veridian E-Journal Silpakorn University, Humanities, Social Sciences and Arts, 8(1), 485-499.

Wang, D. (2004). Push-pull factors in mountain resorts. Chinese Geographical Science, 14(4), 368-376.

Yamane, T. (1967). Elementary sampling theory. Englewood Cliffs, NJ: Prentice Hall.

Yingyoun, T., \& Lertputtharak, S. (2014). Motivation factors, travel behavior and types of tourism of Russian tourists in Pattaya city. Burapha University's Journal of Commerce, 9(2), 81-96. 